\title{
Management and Early Treatment of Status Epilepticus in Adults and Children
}

\section{Çocuk ve Erişkin Status Epileptikuslu Hastaya Yaklaşım ve Erken Dönem Tedavisi}

\author{
Ebru Altındağ 1 , Füsun Ferda Erdoğan², İrsel Tezer ${ }^{3}$, Çiğdem Özkara4 \\ ${ }^{1}$ Istanbul Bilim University Faculty of Medicine, Department of Neurology, Istanbul, Turkey \\ 2Erciyes University Faculty of Medicine, Department of Neurology, Kayseri, Turkey \\ ${ }^{3}$ Hacettepe University Faculty of Medicine, Department of Neurology, Ankara, Turkey \\ ${ }^{4}$ Istanbul University Cerrahpasa Faculty of Medicine, Department of Neurology, Istanbul, Turkey
}

\begin{abstract}
Status epilepticus (SE) is one of the most frequent neurologic emergencies. Generalized convulsive SE, which is the most frequent and easily recognized type of SE, has the highest morbidity and mortality rates. It is important to initiate early and aggressive treatment without delay. In recent years, clinical studies have focused on the prehospital treatment of epileptic seizures. Therefore, written algorithms including prehospital settings will provide rapid application of diagnosis and treatment protocol steps. In this article, the results of the workshop on multidisciplinary treatment of SE are reported in light of new literature.
\end{abstract}

Keywords: Status epilepticus, pharmacotherapy, electroencephalography

$\ddot{O} \mathbf{z}$

Status epileptikus (SE) sık görülen nörolojik acil tablolardan birisidir. En sık görülen ve en kolay tanınan tipi olan jeneralize konvülzif SE mortalite ve morbiditesi en yüksek tablodur. Etkin tedavinin zaman kaybetmeden başlanması önemlidir. Son yıllarda klinik çalışmalar epileptik nöbetin hastane öncesi tedavisi üzerine odaklanmıştır. Bu nedenle hastane öncesi dönemi de içine alan, önceden oluşturulmuş algoritmalar böyle bir hasta ile karşılaşıldı̆̆ında tanı ve tedavi basamaklarının hızla uygulanmasını sağlayacaktır. Bu raporda SE’nin multidisipliner tedavisini güncel literatür 1 şı̆̆ında her yönüyle tartıştığımız çalıştayın sonuçları bildirilecektir.

Anahtar Kelimeler: Status epileptikus, ilaç tedavisi, elektroensefalografi

\section{Introduction}

Most epileptic seizures end within seconds or minutes without requiring intervention. Status epilepticus (SE) is classically an epileptic seizure of longer than 30 minutes, or more than one seizure within this period without the patient recovering or returning to their previous neurologic condition. In recent years, this period has been shortened and was defined as 5 minutes for generalized convulsive status epilepticus (GCSE) in the new identification and classification report of the International League Against Epilepsy (ILAE) (1).
In the simplest form, $\mathrm{SE}$ is divided into 2 groups as convulsive and non-convulsive SE (NCSE). NCSE is a very heterogeneous group with different characteristics in terms of etiology, treatment, and prognosis. NCSE has 3 subgroups, namely absence status epilepticus, complex partial status epilepticus, and subtle SE. Subtle SE is characterized by coma and ongoing electrographic seizure activity, and usually develops in patients with poorly treated GCSE. There is no agreed period of electroclinical seizure activity for NCSE and 30 minutes can be taken as a limit in

Address for Correspondence/Yazışma Adresi: Ebru Altındağ MD, Istanbul Bilim University Faculty of Medicine, Department of Neurology, Istanbul, Turkey Phone: +90 53255971 19 E-mail: draykutlu@hotmail.com ORCID ID: orcid.org/0000-0002-8174-0208

Received/Geliş Tarihi: 06.10.2016 Accepted/Kabul Tarihi: 17.12.2016

${ }^{\circ}$ Copyright 2017 by Turkish Neurological Society

Turkish Journal of Neurology published by Galenos Publishing House. 
practice (2). Classification of SE according to semiology, etiology, electroencephalography (EEG), and age has been proposed in the new classification of the ILAE. NCSE is divided into two groups as accompanied and not accompanied by coma, and the NCSE + coma subgroup is named as subtle SE; patients with epilepsy are in the non-coma group. This group is divided into two groups, namely generalized and focal. Autonomic SE was defined as SE without discrimination between focal and generalized SE in the epileptic group (1).

GCSE, which is the most frequent and easily recognized type of $\mathrm{SE}$, has the highest morbidity and mortality rates. It is important to start effective treatment without losing time. In recent years, clinical trials have demonstrated the importance of prehospital care. For this reason, pre-established algorithms, including the prehospital period, will lead to the rapid application of diagnostic and treatment steps in case of such patients presenting.

\section{Approach to Patients with Status Epilepticus}

GCSE requires fast and effective treatment due to its high mortality rate and its potential for permanent damage. SE treatment includes steps such as supportive care, termination of seizure activity with intravenous (IV) anti-epileptic drugs (AEDs), prevention of seizure recurrence, correction of the causes, prevention of complications, and treatment of developed complications (Figure 1). Initial assessment, supportive care, and examinations for causative agents should never delay early seizure treatment (3).

While applying the treatment steps, information as to whether the patient has epilepsy, AEDs used and their doses, disruption in treatment and/or any intervening treatments should be learned. Then, causes that may lead to SE, such as metabolic disorder, intoxication, infection, or the presence of a new structural lesion, should be investigated. Serum levels should be checked if the patient is using AEDs. Etiologic investigations and patient followup should be continued even if the seizures stop rapidly and the patient recovers. Patients should be kept under observation for at least 24 hours with the expectation that SE may recur even if it is treated $(4,5,6)$.

\section{Immediate Surveys in Status Epilepticus}

- Following vascular access, blood samples should be taken for blood gas, glucose, electrolytes, liver and kidney function tests, calcium, magnesium, complete blood count, and AED levels.

- Five $\mathrm{mL}$ serum and $50 \mathrm{~mL}$ urine samples should be stored for toxicologic examinations in cases where these investigations do not clarify the cause.

- A 12-lead electrocardiogram (ECG) should be performed for the diagnosis of myocardial infarction, communication blocks or arrhythmia, and troponin values should be checked.

- Chest X-ray can be performed for possible aspiration.

- According to the clinical status, if necessary, brain imaging and lumbar puncture should be planned without delaying the start of effective treatment. If the medical history of the patient does not explain the cause of SE, cranial computed tomography (CT) may be preferred primarily after the convulsions are under control because it can be applied quickly, has short image acquisition time, and is easier to access; however, cranial magnetic resonance imaging is superior to CT in elucidating the etiology of SE. Some seizurerelated signal changes seen early in cranial MR, which mimic inflammation or ischemia, and are most commonly seen in the hippocampus, neocortex, corpus callosum, and posterior thalamus, should not be considered irreversible brain damage. Lumbar

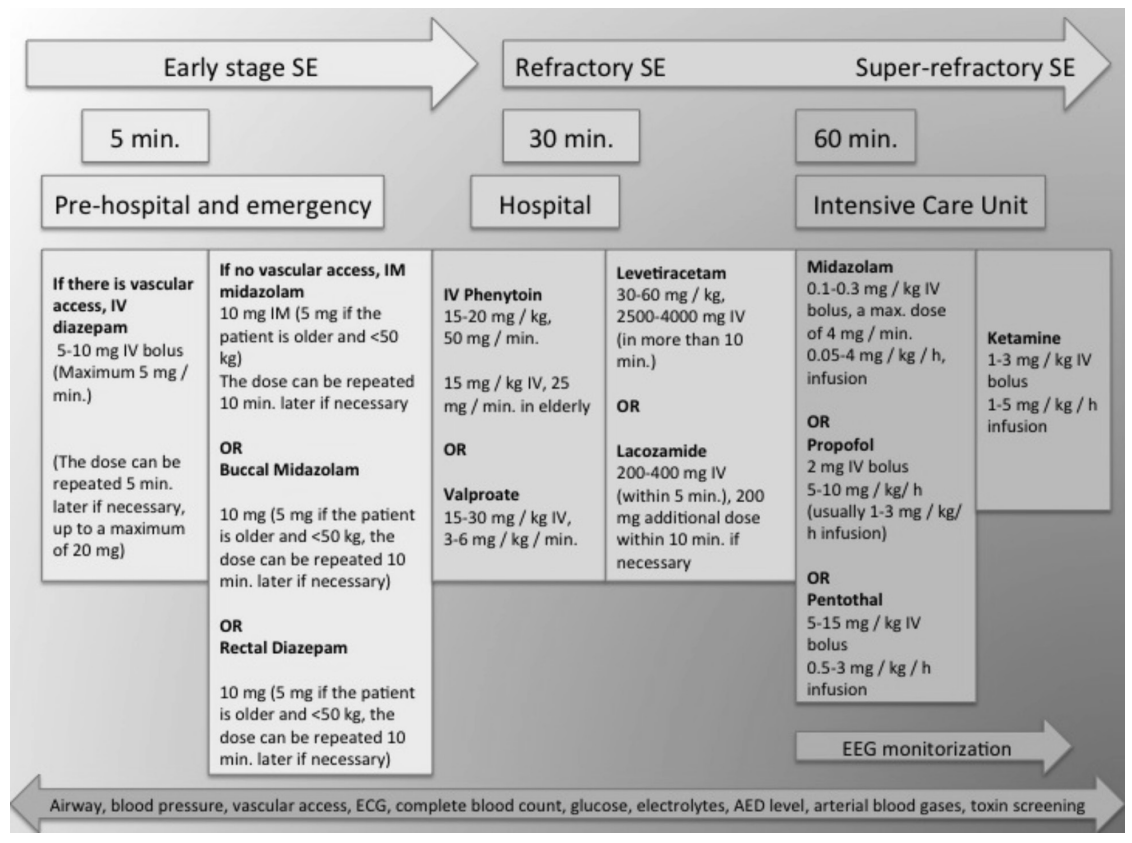

Figure 1. Treatment algorithm in adult patient with status epilepticus

SE: Status epilepticus, IM: Intramuscular, EEG: Electroencephalography, ECG: Electrocardiography, AED: Anti-epileptic drug, min.: Minute, max.: Maximum, IV: Intravenous 
puncture should be performed if inflammatory or infectious central nervous system (CNS) disease is suspected in the etiology of SE.

\section{Monitorization}

- Routine neurologic examination, and regular monitorization of pulse rate, blood pressure, and body temperature should be performed.

- ECG, biochemistry, blood gas, clotting factors, complete blood count, and drug levels should be monitored. Follow-up and treatment of patients with refractory SE who do not respond to first-line AEDs should be performed in intensive care units (ICU) with an anesthetist.

- There is no need for EEG examination and/or EEG monitoring for the diagnosis of GCSE. Rapid and effective treatment should be started without wasting time. However, NCSE or subtle SE should be considered in patients whose consciousness does not recover or in case of unexplained ongoing or fluctuating encephalopathy and coma with/without primary neurologic damage after GCSE, and at least a bedside EEG examination should be performed. If possible, patients should be taken to the ICU and be monitored using EEG.

\section{Drug Treatment of Generalized Convulsive Status Epilepticus}

The pre-hospital treatment of SE is becoming increasingly important because the relationship between resistance and neuronal damage in SE with the duration of SE is known. Besides early and effective treatment, correctable causes such as hypoglycemia and electrolyte disturbance should be detected and corrected rapidly in patients arriving at the hospital. If proconvulsive drug or toxins are suspected, the drug should be discontinued and removed from the body. If there is high body temperature, it must be aggressively reduced.

\section{Early Stage (Stage I)}

This period consists of the prehospital period and the first minutes of hospital admission. Clinical trials have focused on early treatment of SE because the risk of developing resistance and neuronal damage increases as the duration of SE increases. As a result of several prehospital trials, it has been well underlined that SE therapy should be initiated in the emergency department, even in the ambulance. The most important AEDs in this period are benzodiazepines. Benzodiazepines exhibit anti-epileptic activity through binding to GABA-A receptors (7). Following the demonstration of superiority of IV benzodiazepines (clonazepam, lorazepam, and diazepam) over placebo in the termination of SE, there has been an attempt to develop buccal and nasal preparations that can be easily applied in the pre-hospital environment or even at home. IV forms of clonazepam and lorazepam are not available in our country.

\section{Diazepam (IV, Rectal)}

Diazepam is a highly lipid-soluble drug. For this reason, it rapidly spreads to other tissues while rapidly entering brain tissue. The seizure-stopping effect of rectal diazepam in pediatric patients has been known for a long time. The efficacy of both IV and rectal forms in the treatment of SE in adults and pediatrics has been demonstrated in further studies (8). Thirty milligrams of rectal diazepam was reported to be more effective and safer than $20 \mathrm{mg}$ of rectal diazepam.

\section{Lorazepam (IV and Intranasal)}

IV lorazepam is known to be efficacious in SE, but intranasal (IN) lorazepam can also be used. Although its duration of action is longer, it is preferred over diazepam in the early stage of SE due to being less lipid-soluble. In a study comparing IV lorazepam with placebo, IV diazepam and intramuscular (IM) midazolam, it was found to be superior to placebo and diazepam, and reported to be safe in terms of respiratory depression and hypotension. It was concluded that IM midazolam was as effective as IV lorazepam (9). In an open-ended study comparing IN lorazepam with IV lorazepam in pediatric patients, IN lorazepam was reported to be as effective as IV lorazepam, but it is noted that inclusion of patients with SE and patients with single seizures in the emergency clinic increased the success rate (10). However, lorazepam (IV and IN) is not available in our country.

\section{Clonazepam (IV)}

Clonazepam is less lipid-soluble than diazepam. It is the fastest acting benzodiazepine. Although there are positive results in early clinical trials of its use in the early stage of SE, there are no controlled studies comparing IV clonazepam with other drugs, but it is still widely used in some European countries. The IV form of clonazepam is also not currently available in our country (4).

\section{Midazolam (IM, IN, Buccal)}

In a study comparing buccal midazolam with rectal diazepam, its superiority in terms of efficacy and safety was demonstrated in pediatric patients (11). In other studies comparing buccal midazolam with IV diazepam and rectal diazepam, no difference could be demonstrated in terms of efficacy, and as a result, buccal administration of midazolam was recommended when vascular access could not be provided (12). In another study, IM midazolam was reported to be as effective as IV lorazepam, resulting in it being a safe and practical drug (13). In studies comparing IN midazolam with IV diazepam and rectal diazepam, IN midazolam was found to be as effective as IV diazepam, without serious adverse effects, and more effective than rectal diazepam. Buccal midazolam can now be obtained through the Turkish Pharmacists' Association in our country.

\section{II)}

Status Epilepticus Treatment in Hospital (Stage

This is defined as SE that does not respond to first-line benzodiazepine therapy and lasts 10-30 minutes.

\section{Phenytoin (Diphenylhydantoin) (IV)}

Although it has been used in the treatment of SE for 50 years, it has been used with the correct dosage for the last 20 years. Its 
use is not recommended in the early stage of SE due to the low rate of infusion $(50 \mathrm{mg} / \mathrm{min})$ and late-onset of effect. A dose of $1000 \mathrm{mg}$ of phenytoin, which is frequently administered in clinical practice, remains inadequate. It should be administered with a dose of $18-20 \mathrm{mg} / \mathrm{kg}$, and an additional dose of $5-10 \mathrm{mg} / \mathrm{kg}$ of phenytoin should be administered if seizures continue despite the initial dose. Blood phenytoin levels should be targeted to be $20-30 \mu \mathrm{g} / \mathrm{mL}$ in this way. Phenytoin is not a sedative, but hypotension and cardiac arrhythmia are more common, especially in older patients and those with premorbid heart disease. For this reason, cardiac monitoring during administration and slower infusion rate with a lower dose $(15 \mathrm{mg} / \mathrm{kg})$ is required in this age group. During the application, local irritation, thrombophlebitis, compartment syndrome, and purple glove syndrome may develop as a result of extravasation. Despite its long-term use, there are 9 studies comparing phenytoin with other drugs, 4 of which were randomized. In one of these studies, IV lorazepam, IV diazepam + phenytoin, IV phenytoin alone, and IV phenobarbital (PB) alone were compared, and IV lorazepam was found to be superior to phenytoin alone (14). In the other three studies, diphenylhydantoin (DPH) was compared with valproate (VPA), and although VPA was as effective as phenytoin in a meta-analysis of these studies, adverse effects were more common in the DPH group (15). Fosphenytoin may be preferred over phenytoin due to the fact that it can be administered faster, has less arrhythmic and hypotensive adverse effects, and less risk of soft tissue necrosis in cases of extravasation. However, fosphenytoin cannot be found in our country.

\section{Valproate (IV)}

With VPA being effective in all types of seizures, and having well-known risk and adverse effect profiles, it is the most widely prescribed AED in the world. The rapid effects of IV VPA have been demonstrated in various SE models. An efficacy of $70.9 \%$ was reported in a large number of studies, including six randomized controls. The most frequently recommended effective dosage is $15-45 \mathrm{mg} / \mathrm{kg}$ bolus $(6-10 \mathrm{mg} / \mathrm{kg} / \mathrm{min}$ ), followed by $1-3 \mathrm{mg} / \mathrm{kg} / \mathrm{h}$ infusion therapy (16). High infusion rates, such as $40 \mathrm{mg} / \mathrm{kg} / \mathrm{min}$, have also been reported in patients in the ICU. It has no sedative effect. Dizziness, thrombocytopenia and mild hypotension have been reported in less than $10 \%$ of patients. While it has advantages such as not causing cardiovascular and respiratory problems, caution should be exercised against hyperammonemic encephalopathy.

\section{Levetiracetam (LEV) (IV)}

LEV is a well-tolerated AED with broad-spectrum activity, low protein binding, and minimal hepatic metabolism. IV LEV has been in use since 2006. Rapid anti-epileptic activity has been shown in animal models, especially when used in combination with diazepam. Several retrospective case series, including approximately 1000 patients, and prospective safety studies have demonstrated efficacy in various forms of SE. It is used reliably with its lower adverse effects profile, including most commonly, somnolence and sedation, and rarely thrombocytopenia and agitation. In a meta-analysis involving ten studies, an efficacy rate of $44-94 \%$, which was more than retrospective studies, was reported in 234 patients (17). In a more recent meta-analysis, LEV, VPA, and PB were recommended as first-line treatment in benzodiazepine-resistant SE, whereas DPH is not recommended in this case. In a recent randomized, open-ended study, DPH was compared with IV lorazepam in the early stage of SE and it was found to be as effective as IV lorazepam with less respiratory adverse effects (18). This pilot study was important for noting that LEV may be an alternative to IV lorazepam in the early stages.

\section{Phenobarbital (IV, IM)}

In a randomized controlled trial, IV PB was found to be as effective as diazepam + DPH (19). In another study, it was concluded to be as effective as lorazepam. It is not the first choice due to the fact that its respiratory depression effect is higher after diazepam. The most important disadvantages are sedation, respiratory depression, and hypotension. The recommended loading dose is $10-20 \mathrm{mg} / \mathrm{kg}$. It is recommended that it should be administered at a dose of $100 \mathrm{mg} / \mathrm{min}$ for 7 minutes with close clinical follow-up, respiration, and blood pressure monitoring. At present, IV and IM forms are not available in our country.

\section{Lacosamide (LCM) (IV, PO)}

The use of LCM, which improves the slow inactivation of voltage-gated sodium channels, as an AED, is more based on case reports and case series. The most commonly used dosage and form for adults is 200-400 $\mathrm{mg}$ administered as rapid IV infusion over 5-10 minutes. In a study in which only $20 \%$ of patients were refractory CSE, SE was treated in $56 \%$ of patients and adverse effects, most commonly sedation, were reported in $25 \%$ of patients.

\section{Refractory and Super-refractory Status Epilepticus (Stages III-IV)}

Benzodiazepine- and second-line refractory GCSE constitutes $31-43 \%$ of SE. In this case, the new approach is to start treatment earlier with anesthetic drugs (midazolam, propofol, and barbiturates) within 30-60 minutes instead of alternating secondline AEDs (3). For this reason, these patients should be monitored in the ICU with EEG, if possible. SE that lasts longer than 24 hours despite anesthetic drugs is defined as super-refractory SE.

The studies for refractory and super-refractory SE treatment consist of retrospective case series and studies without control groups. For this reason, there is insufficient evidence-based information to form an algorithm. In two recent reviews, general anesthetics were reported to have no superiority over each other (20). Caution should be exercised when using propofol due to the risk of propofol infusion syndrome, which is characterized by metabolic acidosis, rhabdomyolysis, and renal failure. The infusion rate should not exceed $5 \mathrm{mg} / \mathrm{kg} / \mathrm{h}$, and it should be stopped within 48 hours. Cardiovascular and metabolic complications are seen infrequently with midazolam and mostly with barbiturates. In a prospective study, treatment with anesthetics in refractory and super-refractory SEs has been reported to increase infection and increase mortality by 2.9-fold. Other than these, isoflurane (inhalation), etomidate (IV), and ketamine (IV) can also be used. Ketamine acts through N-methyl-D-aspartate (NMDA) receptors and does not cause hemodynamic insufficiencies unlike other 
anesthetics. In different case series, $0.6-10 \mathrm{mg} / \mathrm{kg} / \mathrm{h}$ maintenance dose after a $1-2 \mathrm{mg} / \mathrm{kg}$ loading dose was used for a minimum of 2 hours and a maximum of 27 days. It was used between 1-2nd hours and $140^{\text {th }}$ day of SE, following application of 4-9 different treatments. Cerebellar syndrome with cerebellar atrophy has been reported with high-dose ketamine, and this neurotoxic effect was reported to decrease slightly after about 21 months.

Magnesium used in the treatment of eclampsia also acts on NMDA receptors, but has not received much attention in SE therapy until now. Although there are no controlled studies, it has been reported in case series that infusion to maintain a serum level of $3.5 \mathrm{mmol} / \mathrm{L}$ may be recommended.

It has been reported in various case series that high-dose use of oral topiramate $(2-25 \mathrm{mg} / \mathrm{kg} /$ day in children and $1600 \mathrm{mg} / \mathrm{day}$ in adults), which acts through ionotropic glutamatergic AMPA receptors, may be effective in the treatment of SE, despite the absence of an IV form. Other drugs used in super-refractory SE are LCM (IV), paraldehyde (rectal, IM), lidocaine (IV), chlormethiazole (IV), and carbamazepine (rectal, IV) (4).

Immunotherapy consisting of corticosteroids, IV immunoglobulins (IVIg), and plasma exchange is increasingly being used in super-refractory SE, even in the absence of any definite immunologic disease, due to the presence of antibodies against voltage-gated potassium channels and NMDA receptors, and the detection of role of inflammation in epileptogenesis. Although there are no comparative studies in this regard, more than 50 patients in the literature benefited from immunotherapy. Despite the fact that there is no consensus on the length of treatment, $1 \mathrm{mg} / \mathrm{kg} /$ day for 1 week after $1 \mathrm{~g} /$ day prednisolone for 3 days, and $0.4 \mathrm{~g} / \mathrm{kg} / 5$ days IVIg or plasma exchange therapy is recommended if there is no change within two days. If there is even a partial response, longer corticosteroid therapy or monthly IVIg boosters may be continued, and even cyclophosphamide or rituximab therapy may then be administered (4).

\section{Drug Treatment of Non-convulsive Status Epilepticus}

In general, GCSE treatment is applied in generalized and focal forms of NCSE. In suspected cases, patients are diagnosed using EEG and diazepam, a short-acting benzodiazepine, which is administered intravenously in acute treatment. In cases where EEG cannot be performed, it is also recommended to make a diagnosis by performing a treatment trial. If the diagnosis of generalized form is certain, phenytoin can even be harmful. The response to benzodiazepine treatment in the generalized form is usually permanent. The time until the termination of the seizure in the resistant focal form is less critical than in GCSE. Therefore, it is suggested that non-anesthetic AEDs should be tried before passing on to general anesthetic agents, although not based on evidence. Although no studies have compared AEDs with each other, PB, VPA, and LEV can be applied for this purpose. It should be kept in mind that high doses of PB may cause respiratory depression when an additional dose is required. It is recommended that patients should be monitored under intensive care conditions in this situation. Anesthetic drugs may be administered at the doses used in GCSE in patients with ongoing seizures (2).

\section{Long-term Anti-Epileptic Drugs Treatment}

- Long-term, maintenance AED treatment should be started in parallel with emergency treatment.

- Drug selection should be made according to previous AED treatment, type of epilepsy, and clinical presentation.

- First, AED treatment should be continued at the maximum dose, and the previous dose should be returned if a new dose reduction is made.

- If phenytoin or PB has been used in the emergency treatment, oral or IV maintenance doses should be determined by following serum drug levels, but continuing the treatment with phenytoin or PB is not necessary.

- If necessary, other oral AED treatments should be started at oral loading doses.

- It should not be forgotten that the absorption characteristics of some AEDs might change with nasogastric feeding.

- If the patient is seizure free for 24 hours, and the appropriate blood levels of the maintenance AED are provided, anesthetic drugs should be slowly reduced.

\section{Multidisciplinary Approach to Status Epilepsy in Children}

SE, which is more common in childhood, is an urgent neurologic problem with higher mortality and morbidity in infantile children. Age, etiology, and duration of seizure affect mortality. The incidence in children is $18-23 / 100,000$. Incidence is high due to infectious diseases in developing countries (21).

Despite the fact that the definition is based on seizure duration, every child who is brought to the emergency service with seizure should be practically treated as SE. SE is more frequent in younger children, and febrile SE or an acute symptomatic etiology (CNS infection, vascular events, toxins, electrolyte imbalance, trauma) is detected in $80 \%$ of cases. Cryptogenic or acute symptomatic seizures are seen in older children. This group consists of children with pre-SE neurologic deficits and epilepsy history (22).

Early SE is defined as an acute epileptic condition characterized by continuous generalized convulsive seizures of at least 5 minutes, or non-convulsive and focal seizures of at least 15 minutes (4).

In some children, SE continues despite the use of adequate doses of 2 or 3 anticonvulsant drugs; this condition is called refractory SE. There is no clear definition. Different durations were used as criteria in different studies. Unresponsiveness to different drug treatments without a clear timeframe is the key point. In some children with refractory SE, despite all treatments, SE may last weeks or months, taking the name of malignant refractory SE. It can be de novo, cryptogenic, symptomatic, or febrile SE. Malignant refractory SE may develop due to encephalitis, leading to high morbidity and mortality in previously healthy young children. It is not known whether this is a different disease entity or a variant of refractory SE $(23,24)$.

An ideal treatment protocol has not been identified because of the lack of comparative studies involving large patient groups in childhood SE therapy. There are different treatment protocols applied in different countries or regions. Many guidelines, protocols, and algorithms have been created based on evidence, 
common ideas, and existing drugs. Their basic details are the same with differences in some minor details (23).

Despite similar etiologies, it was observed that mortality was higher in adults with seizures longer than 30 minutes. In children, mortality is mostly related to etiology (24).

\section{Targets in Status Epilepticus Management}

As well as in adulthood, it is necessary to support vital functions (airway, respiration, circulation), and provide adequate cardiovascular functions and brain oxygenation in children. Clinical and electrical seizures should be terminated as soon as possible. In order to prevent the recurrence of seizures, triggers such as fever, infection, electrolyte imbalance, and hypoglycemia should be identified and corrected.

The diagnosis and initial treatment of the life-threatening cause (e.g., meningitis, intracranial hypertension) leading to SE should be made. Prevention of systemic complications and CNS damage should be targeted $(21,22)$.

\section{General Precautions}

\section{Evaluation and stabilization of vital functions:}

Ensuring airway is open

- Proper head position,

- Aspiration, oropharyngeal tube placement and oxygenation.

\section{Respiration}

- Ensuring effective ventilation (oxygen administration, if necessary, bag ventilation after nasogastric tube insertion), and intubation if bag ventilation is ineffective.

\section{Circulation}

- Providing adequate perfusion,

- Monitoring vital signs (heart rate, respiration, blood pressure, and $\mathrm{O}_{2}$ saturation),

- Maintaining vascular access,

- Complete blood count and analyses of serum levels of glucose, blood gases, electrolytes, $\mathrm{Ca}, \mathrm{Mg}, \mathrm{C}$-reactive protein, urea, creatinine,

- Treatment of hypoglycemia/hypovolemia/fever/acidosis/ electrolyte imbalance,

- Administration of AED,

- Vital signs should be monitored continuously and cardiorespiratory depression should be minded,

- Examinations for the cause of SE and treatments should be considered, metabolic disorders should be assessed and blood pressure should be monitored,

- EEG monitoring should also be initiated and the effectiveness of the treatment should be monitored $(21,22)$.

\section{Conclusion}

In conclusion, $\mathrm{SE}$ is one of the most common neurologic emergency conditions with etiology-, age-, and comorbidityrelated morbidity and mortality. It is important to establish treatment protocols to cover the pre-hospital period so that the diagnosis and treatment steps can be implemented quickly when such a patient is encountered. For this purpose, diagnosis and treatment steps were reviewed in the "Multidisciplinary Approach to Early Diagnosis and Treatment of Status Epilepticus Workshop", which was held with the participation and contribution of a total of 78 participants, including 13 experienced epilepsy specialists, and a treatment protocol was developed for both childhood and adulthood, including early-stage and prehospital treatment that was particularly highlighted in recent publications (Figure 1, 2). Recent randomized controlled trials have shown that IV lorazepam or IM midazolam is the most effective treatment in early stage SE. Buccal midazolam is advantageous because it is noninvasive, easy

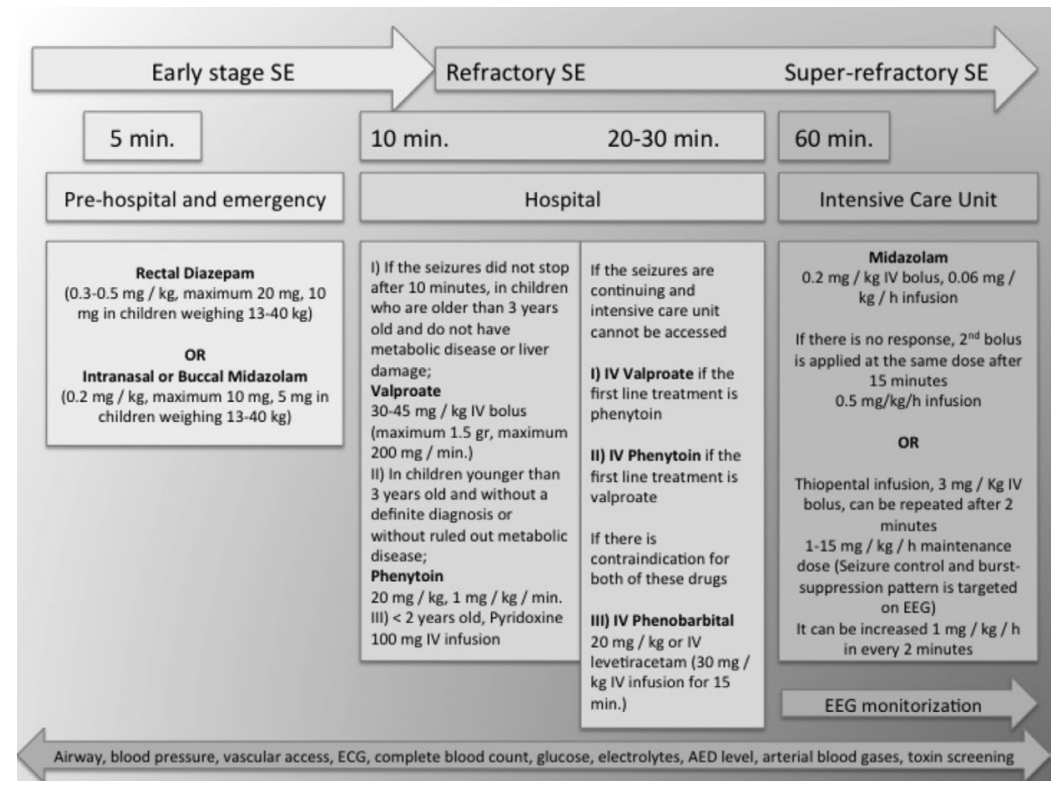

Figure 2. Treatment algorithm in pediatric patient with status epilepticus SE: Status epilepticus, EEG: Electroencephalography, ECG: Electrocardiography, AED: Anti-epileptic drug, min.: Minute, max.: Maximum, IV: Intravenous 
and faster to administer, and it can be easily and safely applied by paramedics in the ambulance. Because of the lack of lorazepam and fosphenytoin in our country, 5-10 $\mathrm{mg}$ of IV bolus diazepam is given as the first-choice treatment, followed by DPH, VPA, LEV, or LCM according to the clinical findings of the patient and accompanying diseases. Instead of diazepam, IM midazolam may be preferred in a patient without a vascular access. The new approach in refractory $\mathrm{SE}$ is to initiate general anesthetics in the early stage within 3060 minutes. Immune etiologies should be considered in superrefractory SEs and immunotherapy should be tried.

\section{Acknowledgment}

We would like to thank the following speakers whose names are given in alphabetical order below for their participation and contributions to the Multidisciplinary Approach to Early Diagnosis and Treatment of Status Epilepticus Workshop, which was organized by the Turkish Chapter of the International League Against Epilepsy and the Turkish Neurological Society on April 8, 2016.

Dr. Betül Baykan, Dr. Nerses Bebek, Dr. Ayşe Güler, Dr. Candan Gürses, Dr. Şenay Haspolat, Dr. Perihan Ergin Özcan, Dr. Sema Saltık, Dr. Hadiye Şirin, Dr. Özlem Kayım Yıldız.

\section{Ethics}

Peer-review: Externally peer-reviewed.

\section{Authorship Contributions}

Surgical and Medical Practices: E.A., F.F.E., İ.T., Ç.Ö., Concept: İ.T., Ç.Ö., Design: İ.T., Ç.Ö., Data Collection or Processing: E.A., F.F.E., Analysis or Interpretation: E.A., F.F.E., Literature Search: E.A., F.F.E., Writing: E.A., F.F.E.

Conflict of Interest: No conflict of interest was declared by the authors.

Financial Disclosure: The authors declared that this study received no financial support.

\section{References}

1. Trinka E, Cock H, Hesdorffer D, Rosetti AO, Schffer IE, Shinnar S, Shorvon S, Lowenstein DH. A definition and classification of status epilepticus-Report of the ILAE Task Force on Classification of Status Epilepticus. Epilepsia 2015;56:1515-1523.

2. Hirsch LJ, Gaspard N. Status epilepticus. Continuum (Minneap Minn) 2013;19:767-794

3. Betjemann JP, Lowenstein DH. Status epilepticus in adults. Lancet Neurol 2015;14:615-624.

4. Trinka E, Höfler J, Leitinger M, Brigo F. Pharmacotherapy for status epilepticus. Drugs 2015;75:1499-1521.

5. Rosenow F, Knake S. Status epilepticus in adults. In: Stefan H, Theodore WH, (eds). Handbook of Clinical Neurology. Epilepsy, Part II. Amsterdam: Elsevier, 2012;108:813-819.

6. Mazurkiewicz-Bełdzińska M, Szmuda M, Zawadzka M, Matheisel A. Current treatment of convulsive status epilepticus-a therapeutic protocol and review. Anaesthesiology Intensive Ther 2014;46:293-300.
7. Trinka E. Benzodiazepines used primarily for emergency treatment (diazepam, lorazepam and midazolam). In: Shorvon SD, Perucca E, Engel Jr J, (eds). Treatment of epilepsies. 3rd ed. Oxford: Blackwell Publishing, 2009:470-484.

8. Cereghino JJ, Cloyd JC, Kuzniecky RI; North American Diastat Study Group. Rectal diazepam gel for treatment of acute repetetive seizures in adults. Arch Neurol 2002;59:1915-1920.

9. Prasad M, Krishman PR, Sequeira R, Al-Roomi K. Anticonvulsant therapy for status epilepticus. Cohrane Database Syst Rev 2014:CD003723.

10. Arya R, Gulati S, Kabra M, Sahu JK, Kalra V. Intranasal versus intravenous lorazepam for control of acute seizures in children: a randomized openb-label study. Epilepsia 2011;52:788-793.

11. McIntyre J, Robertson S, Norris E, Appleton R, Whitehouse WP, Phillips B, Martland T, Berry K, Collier J, Smith S, Choonara I. Safety and efficacy of buccal midazolam versus rectal diazepam for emergency treatment of seizures in children: a randomised controlled trial. Lancet 2005;366:205-210.

12. Jones S, Pahl C, Trinka E, Nashef L. A protocol for the inhospital emergency drug management of convulsive status epiepticus in adults. Pract Neurol 2014;14:194-197.

13. Silbergleit R, Durkalski V, Lowenstein D, Conwit R, Pancioli A, Palesch Y, Barsan W, NETT Investigators. Intramuscular versus intravenous therapy for prehospital status epilepticus. N Engl J Med 2012;366:591-600.

14. Treiman DM, Meyers PD, Walton NY, Collins JF, Colling C, Rowan AJ, Handforth A, Faught E, Calabrese VP, Uthman BM, Ramsay RE, Mamdani MB. A comparison of four treatments for generalized convulsive status epilepticus. Veterans affairs status epilepticus cooperative study group. N Eng J Med 1998;339:792-798.

15. Trinka E. What is the relative value of the standard anticonvulsants: phenytoin and fosphenytoin, phenobarbital, valproate, and levetiracetam? Epilepsia 2009;50(Suppl 12):40-43.

16. Trinka E, Höfler J, Zerbs A, Brigo F. Efficacy and safety of intravenous valproate for status epilepticus: a systemic review. CNS Drugs 2014;28:623629.

17. Zelano J, Kumlien E. Levetiracetam as alternative stage two antiepileptic drugin in status epilepticus: a systemic review. Seizure 2012;21:233-236.

18. Yasiry Z, Shorvon SD. The relative effectiveness of five antiepileptic drugs in treatment of benzodiazepine-resistant convulsive status epilepticus: a metaanalysis of published studies. Seizure 2014;23:167-174.

19. Shaner DM, McCurdy SA, Herring MO, Gabor AJ. Treatment of status epilepticus: a prospective comparison of diazepam and phenytoin versus phenobarbital and optional phenytoin. Neurology 1988;38:202-207.

20. Ferlisi M, Shorvon S. The outcome of therapies in refractory and superrefractory convulsive status epilepticus and recommendations for therapy. Brain 2012;135:2314-2328.

21. Abend NS, Loddenkemper T. Pediatric Status Epilepticus Menegament. Curr Opin Pediatr 2014;26:668-674.

22. Cappovilla G, Beccarra F, Minicucci F, Sartori S, Vecchi M. Treatment of Convulsive Status Epilepticus in Childhood; Recommendations of the Italian League Against Epilepsy. Epilepsia 2013;54(Suppl 7):23-34.

23. Glauser T, Shinnar S, Gloss D, Alldredge B, Arya R, Bainbridge J, Bare M, Bleck T, Dodson WE, Garrity L, Jagoda A, Lowenstein D, Pellock J, Riviello J, Sloan E, Treiman DM. Evidence-Based Guideline: Treatment of Convulsive Status Epilepticus in Children and Adults: Report of the Guideline Committe of the American Epilepsy Societty. Epilepsy Curr 2016;16:48-61.

24. Gower EH, Nazzal Y, Hirsch 1. Traetment of Convulsive Status Epilepticus. Curr Treat Options Neurol 2016;18:11. 